\title{
Enhanced chemosensitivity to CPT-11 in colorectal carcinoma xenografts by small hairpin RNA interference targeting PLK1
}

\author{
P. FAN, S. ZHANG, H. TIAN, N. YAN, L. DAI, X. ZHANG, L. CHENG, C. LI, Y. LI, X. CHEN, G SHI, Y YANG, Y. WEI, H. DENG*
}

State Key Laboratory of Biotherapy, West China Hospital, Sichuan University, Ke-yuan Road 4,No. 1, Gao-peng Street, Chengdu, Sichuan, 610041, China

${ }^{*}$ Correspondence: denghongx@scu.edu.cn

Received March 6, 2012 / Accepted June 16, 2012

\begin{abstract}
Commonly used drugs for the treatment of colon cancer patients like CPT-11 shows severe side effects or induces resistance in clinical settings. Thus, we analyzed a combination of PLK1 (polo-like kinase 1)-specific short hair RNA (shRNA), a potent tool to destroy mitosis in cancer cells, together with CPT-11 to enhance drug sensitivity. Cellular proliferation and apoptosis were determined in SW620 colorectal carcinoma cells. Knockdown of cellular PLK1 led to the decreased mRNA and PLK1 protein in RT-PCR and western blot assay. The viability declined $(\mathrm{p}<0.001)$ in MTT assay and colony formation assay, and the number of apoptotic cells was clearly increased $(\mathrm{p}<0.01)$ in flow cytometric analysis and Hoechst 33258 staining compared with control cells after incubation with PLK1-specific shRNA and SN-38. We found the level of cleaved PARP was also increased in vitro. In vivo, employment of shRNA targeting PLK1 improved the sensitivity to treat SW620 nude mouse model toward CPT-11. The combination therapy inhibited cellular proliferation and promoted apoptosis observed at the percentage of PCNA and caspase 3 by immunohistochemistry, accompanied with TUNEL assay. As we expect, the combination treatment delayed tumor growth $(\mathrm{p}<0.01)$ and simultaneously reduced tumor weight $(\mathrm{p}<0.01)$ compared with control group. Taken together, combination of PLK1-specific shRNA interference with low-dose CPT-11 triggered a antitumor efficacy and represented a potential strategy to treat colon cancer.
\end{abstract}

Key words: CPT-11, drug resistance, SN-38, PLK1, RNA interference, colorectal carcinoma

PLK1, a serine/threonine kinase, is the best characterized among polo family. A key cell cycle regulator was over-expressed in various human tumors, but the expression of PLK1 is very low or undetectable in most other adult tissues [1-3]. Thus, PLK1 is a potentially important therapeutic target. Evidence from a study showing that over-expression of PLK1 in NIH3T3 fibroblasts transformed the cells, stimulate the cells to grow in soft agar and form tumors when injected into nude mice [4]. So far, the feasible approach is to explore Plk1 inhibitor blocking its function on the cell cycle progression or the antitumor drug target including small molecules, antisense oligonucleotides, small interference (si)RNA and so on [5-7]. It was reported that down-regulation of PLK1 expression or function could inhibit cell proliferation, advance apoptosis, sensitize the tumor cells to the antitumor agents and inhibit tumor growth in mice [8-15]. Wonderfully, RNA interference is an effective strategy for gene silencing that directly transfected into tumor cells to knock down endogenous gene expression [6].
CPT-11, a water-soluble derivative of camptothecin, has broad anti-tumor activity and is a promising anti-cancer drug in clinical trials $[16,17]$. SN-38, a metabolite of CPT-11, is responsible for anti-tumor activity [18]. CPT-11 monotherapy or in combination with several chemotherapy drugs, has been approved as first- or second-line chemotherapy for the treatment of patients with colorectal cancer [19-22]. CPT-11 has also proved anticancer activity against a variety of solid tumors in preclinical and clinical trials $[23,24]$. But CPT-11based schedules often cause severe side effects at a high dose including mainly delayed diarrhoea, hematopathy [25]. These questions usually led to discontinuous therapy, finally reducing the efficacy of therapy.

In the present study, numerous experiments are used to evaluate which is an optimal regimen to decrease toxicity and reduce dosage during chemotherapy. Interference (si)RNA is more specific and more potent under development which mediate post-transcriptional gene silencing [26]. The RNA 
interference technology as a promising approach is employed for target therapy. Meanwhile, plasmid encoded for the short hairpin RNA (shRNA) expression system is applied to silencing targeted gene due to its trait of cheap, easy to operate and effectiveness [8].

In our study, we investigate plasmid expression short hairpin RNA (shRNA) targeting PLK1 combined with low-dose SN-38 to treatment with SW620 colorectal carcinoma in vitro and with low-dose CPT-11 to therapy SW620 xenograft nude model in vivo.

\section{Materials and methods}

Plasmids construction. Short hairpin (sh)RNA expression plasmids were designed based on the pGensil-2.4/U6 parental vector from Genesil Biotechnology Company (Genesil Biotechnology Company, Wuhan, China) and constructed by our lab. The PLK1shRNA contained a specific sequence to target human PLK1 mRNA (5'-CCT TGATGAAGAAGATCAC-3'). The control sequence, called $\mathrm{KB}$, had no homology to any mammalian sequence (5'GACTTCATAAGGCGCATGC-3’). The sequences were inserted into the pGensil-2.4/U6 vector to generate recombinant plasmids, were named pshPLK1 and pshKB, respectively.

Cell culture and transfection. The human Adenocarcinoma of Colon Cell Line SW620 was purchased from ATCC (Rockville, MD, USA). Cells were maintained as adherent monolayer in Dulbecco's modified Eagle's medium (DMEM) containing $10 \%$ fetal bovine serum (FBS) and $100 \mathrm{U} / \mathrm{ml}$ penicillin and $100 \mathrm{U} / \mathrm{ml}$ streptomycin in a humidified $\left(37^{\circ} \mathrm{C}\right.$, $5 \% \mathrm{CO} 2$ ) incubator.

$2 \times 10^{5}$ cells were plated into 6-well plates and allowed to adhere for $24 \mathrm{~h}$. Cell transfection was performed using FugeneHD (Roche, Mannheim, Germany) according to the manufacturer's recommendation. $2 \mu \mathrm{g}$ plasmid DNA (pshKB or pshPLK1) and $5 \mu$ FugeneHD were diluted in serum-free DMEM, gently mixed, and then incubated at room temperature for $20 \mathrm{~min}$ before it was added into the cell cultures. Growth medium was used as a control agent. Cells were harvested at $72 \mathrm{~h}$ after transfection for RT-PCR, western blot assays. All experiments were performed in three replicates.

Semiquantitative RT-PCR. The total RNA from tumor cells was extracted using TRIzol Reagent (Invitrogen, Grand Island, NY) according to the manufacturer's protocol. RNA concentration was measured by UV absorbance spectroscopy. The RT-PCR was performed with the isolated total RNA using one step RT-PCR kit (Takara, Japan). The GAPDH was amplified as an internal control. The sequences of PLK1 primers were PLK1-F: 5'-CGAGTTCTTTACTTCTGGCTAT-3'and PLK1-R: 5'-GGAGACTCAGGCGGT-ATGT-3'. RT-PCR conditions were as follows: reverse transcription for $30 \mathrm{~min}$ at $50^{\circ} \mathrm{C}$ and enzyme inactivation for $2 \mathrm{~min}$; amplification 25 cycles for $0.5 \mathrm{~min}$ at $94^{\circ} \mathrm{C}$, annealing for $0.5 \mathrm{~min}$ at $55^{\circ} \mathrm{C}$, and extension for $0.5 \mathrm{~min}$ at $72^{\circ} \mathrm{C}$; followed by a terminal elongation for $10 \mathrm{~min}$ at $72^{\circ} \mathrm{C}$. The RT-PCR products were checked by electrophoresis on a $1.5 \%$ agarose gel, imaged by Quantity one (Bio-Rad).

MTT assay. $4 \times 10^{3}$ cells per well were seeded into 96-well plates, allowed to adhere overnight. 24 hours after transfection with pshKB or pshPLK1, cells were treated with different concentration of SN-38(30,60, 120, 240nM, sigma), MTT (Sigma, Poole, Dorset, England) solution was added 48 hours later. Then, the plates were incubated for 4 hours $\left(37^{\circ} \mathrm{C}, 5 \%\right.$ $\mathrm{CO}_{2}$ ) to make the viable cells form formazan crystals what were dissolved in $40 \%$ SDS solution overnight. The absorbance was determined at wavelength of $570 \mathrm{~nm}$. For analysis of cell viability, values were subtracted for background correction. Each assay was performed in triplicate.

Colony formation assay. To determine the effect on proliferation of pshPLK1 combination with SN-38 to SW620 cells, cells were treated with pshKB, pshPLK1, SN-38 or pshPLK1+SN-38(plasmid DNA $2 \mu \mathrm{g}, \mathrm{SN}-3860 \mathrm{nM}$ ), untreated ones as a control. After 72 hours, the cells at a density of 1000 were seed into 6-well plates respectively. Incubated for 12 days $\left(37^{\circ} \mathrm{C}, 5 \% \mathrm{CO}_{2}\right)$, the cells were stained by crystal violet for 20 minutes and more than 50 cells as a colony. Each assay was performed on three replicates.

Flow cytometric analysis. To check pshPLK1 conbination with SN-38 on cell apoptosis, SW620 cells were added to 6well plates at a density of $30 \%$ overnight. After treatment with pshKB, pshPLK1, SN-38 or pshPLK1+S for 72 hours (plasmid DNA $2 \mu \mathrm{g}, \mathrm{SN}-3860 \mathrm{nM}$ ), the cells were harvested, then washed with PBS and resuspended in propidium iodide/RNase A solution, untreated cells as the control. The samples were evaluated by flow cytometry $30 \mathrm{~min}$ later. Each experiment was performed on three times.

Western bolt analysis. The transfected cells were directly fractured in RIPA lysis buffer (50 mM Tris-HCl; $150 \mathrm{mM}$ $\mathrm{NaCl} ; 1 \mathrm{mM} \mathrm{EDTA} ; 1 \%$ NP-40; $0.25 \%$ Na-deoxycholate; $1 \mathrm{mM}$ Na3VO4; $1 \mathrm{mM} \mathrm{NaF;} 1 \mathrm{mM}$ PMSF; $1 \mathrm{mg} / \mathrm{ml}$ aprotinin). And tissue proteins from each group were extracted after pulverized in liquid nitrogen and clarified by centrifugation at $10,000 \mathrm{~g}$ for $30 \mathrm{~min}$ and the supernatant was collected. Protein concentration was quantified with Bradford assay. The proteins were separated on $10 \%$ SDS-PAGE by electrophoresis and then transferred onto PVDF membranes (Millipore, Bedford, MA). After incubation in 5\% nonfat milk for 1 hour at room temperature, the membranes were probed with specific antibodies overnight at $4^{\circ} \mathrm{C}$. And after that the membranes were incubated with secondary antibodies for 1 hour at room temperature. The peroxidase-labeled bands were detected by enhanced chemiluminescence (Pierce, Rockford, IL, USA).

Preparation of plasmid DNA: liposome complexes. The cationic liposome consisted of DOTAP (Alabaster, AL, USA) and cholesterol (St. Louis, MO, USA), mixed at a 1:1 molar rate in chloroform, and finally manufactured freeze-dried discoid. Before injection in vivo, the cationic liposome was dissolved in sterile water. After that, $25 \mu \mathrm{g}$ DOTAP: Chol and $5 \mu \mathrm{g}$ plasmid DNA were added into 5\% dextrose solution 
sequentially to produce complexes. The forming mixture was incubated at room temperature for $30 \mathrm{~min}$ before administration into mice.

Tumor xenograft model and treatment in vivo. All the animal procedures were approved by the Institutional Animal Care and Use Committee of Sichuan University (Chengdu, Sichuan, China). $5 \times 10^{6}$ tumor cells were inoculated subcutaneously into female nude mice (BALB/c , $5-6$ weeks of age). The mice bearing tumors around $80 \mathrm{~mm}^{3}$ were selected and randomly assigned to five independent treatment groups (4 mice per group): (a) 5\%GS (glucose solution), (b) pshKB, (c) pshPLK1, (d) CPT-11 (Hengrui medicine, Jiangsu, China), (e) pshPLK1 combination with CPT-11. The formed complexes were administrated into mice by tail vein injection thrice a week for four weeks. A week after initial pshPLK1/liposome complex treatment, CPT-11 $(20 \mathrm{mg} / \mathrm{kg})$ was administered twice a week for 3 weeks also through tail intravenous injection. During treatment, tumor dimension was measured every 3 days, and tumor volume was calculated as follows: tumor volume $=$ length $\times$ width $^{2} / 2$. Total 4 weeks later, the mice were sacrificed. The peeled tumor tissues were weighted then fixed in $4 \%$ paraformaldehyde, finally paraffin-embedded for histology and TUNEL assay.

Immunohistochemistry. The expression level of PLK1, PCNA and Caspase 3 were measured by performed with mouse anti-human PLK1 antibody (Millipore Biotechnology, Bedford, MA); mouse anti-human PCNA antibody (Santa Cruz Biotechnology, Santa Cruz, CA, USA) and Rabbit antihuman Caspase3 antibody (Abcam, Cambridge, UK) on paraffin sections. The slices were subsequently incubated with corresponding secondary antibodies, colored with DAB afterwards counterstain. The immunohistochemistry procedures were according to manufacturer's protocol. Five areas on each slice were randomly chosen and analyzed. All specimens were scanned at middle power magnification $(\times 400)$.

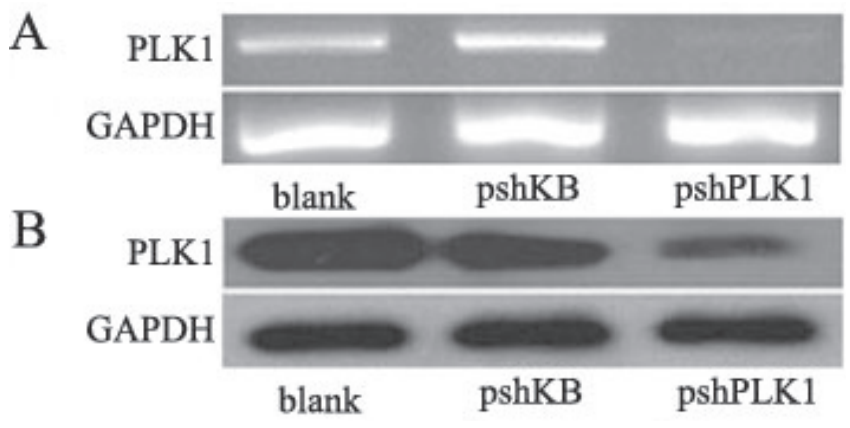

Figure 1. Knockdown of PLK1 in SW620 colorectal carcinoma cells in vitro 72 hours after transfected with pshPLK1, RT-PCR and Western blot were performed. (A) PLK1 mRNA was semiquantified by RT-PCR. The GAPDH gene was used as an internal control. (B) Antibody against PLK1 and GAPDH as a loading control.
In situ TUNEL assay for apoptotic cells. TUNEL assay was used to further detect apoptotic cells in tumor tissues according to the manufacturer's protocol (Promega, San Luis Obispo, CA, USA). The TUNEL-positive cells were monitored and imaged under the fluorescence microscope at middle power magnification $(\times 200)$. For each treatment group, the number of apoptotic cells was counted in five randomly captured images.

Statistical analysis. SPSS 11.5 was used for statistical analysis. Data were analyzed statistically using one-way ANOVA followed by the Tukey test. A value of $\mathrm{P}<0.05$ was considered significant.

\section{Results}

Specific knockdown of PLK1 in SW620 colorectal carcinoma cells in vitro. The pshPLK1 and the pshKB were transiently transfected into SW620 cells, respectively. The transfected cells were harvested at $72 \mathrm{~h}$, and the expression level of PLK1 was analyzed by RT-PCR and Western blot. As shown in Fig.1A and Fig.1B, the level of mRNA was decreased in pshPLK1 group, western blot analysis indicated suppression of PLK1 protein expression was observed in transfected pshPLK1 group compared with untreated group in SW620 cells. These results implicated pshPLK1 can specifically inhibit PLK1expression in SW620 cells.

The effect on cell proliferation and apoptosis in vitro. To examine knockdown of PLK1 enhancing cells sensitive to $\mathrm{SN}-38$, we assigned blank, pshKB, pshPLK1, SN-38, pshPLK1+SN-38. MTT and colony formation were used to evaluate the effects of pshPLK1 and SN-38 on cell proliferation. After incubation for 12 days, a decrease in the amount of colonies in SW620 cells was observed in combination treatment group correspondingly a appropriate decrease in pshPLK1 alone and $\mathrm{SN}-38$ alone groups (Fig.2A and 2B). Also, MTT assay conforms to the results above. MTT results indicated SW620 cells proliferation in a time- and dose-dependent manner to $\mathrm{SN}-38$. The pshPLK1 combined with $\mathrm{SN}-38(60 \mathrm{nM})$ is superior to the other concentration, considering the cytotoxicity of SN-38 and the effect on the cells (Fig.2C). In summary, pshPLK1 combined with low-dose SN-38 could reduce the survival capacity of SW620 cells.

Apoptosis was evaluated by flow cytometry. SW620 cells were treated pshKB, pshPLK1, SN-38, pshPLK1+SN-38, untreated cells were the control. As shown in Fig.2D, pshPLK $1+\mathrm{SN}-38$ treatment later, the proportion of apoptosis was increased to $42.6 \%$ (blank $2.2 \%$, pshKB $2.2 \%$, pshPLK1 9.1\%, SN-38 27.0\%). These results revealed that pshPLK1 combined with low-dose SN-38 could induce greater apoptosis than the other two treatment groups, given an additive effect.

Antitumor effect and expression of PLK1 in vivo. Our experiments demonstrated that pshPLK1 efficiently inhibited cell proliferation and induced apoptosis of SW620 cells in vitro. Therefore, we further investigated the antitumor effect of pshPLK1 and low-dose CPT-11 monotherapy or combination 
A

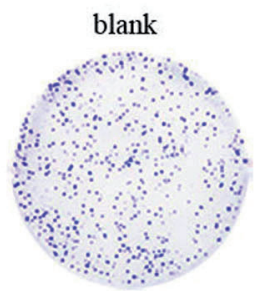

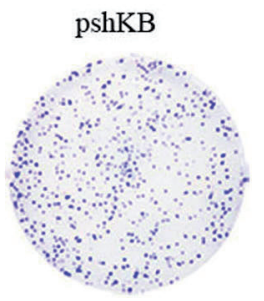
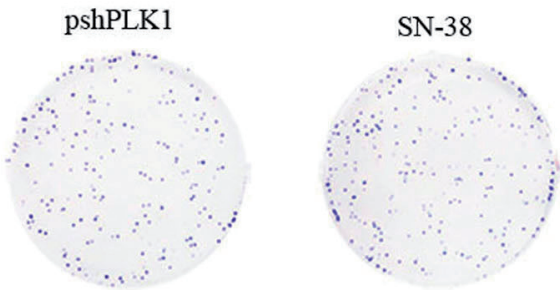

pshPLK1+S

B

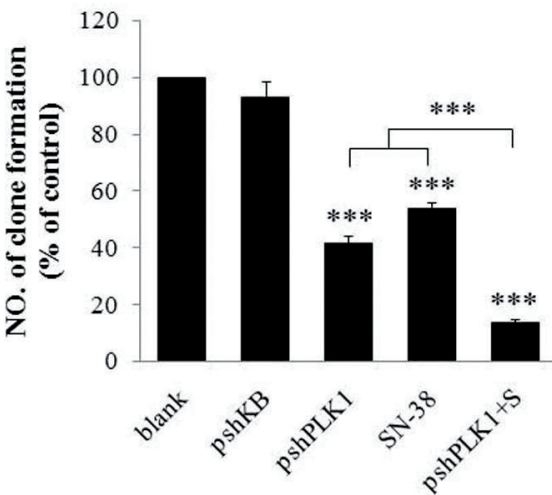

$\mathrm{D}$

blank

pshKB

pshPLK1
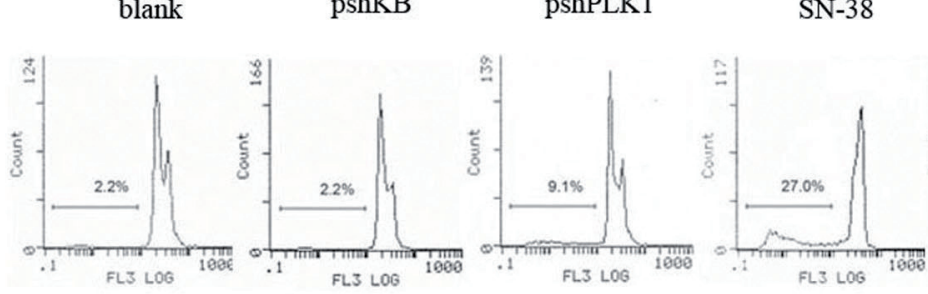

SN-38

$\mathrm{C}$

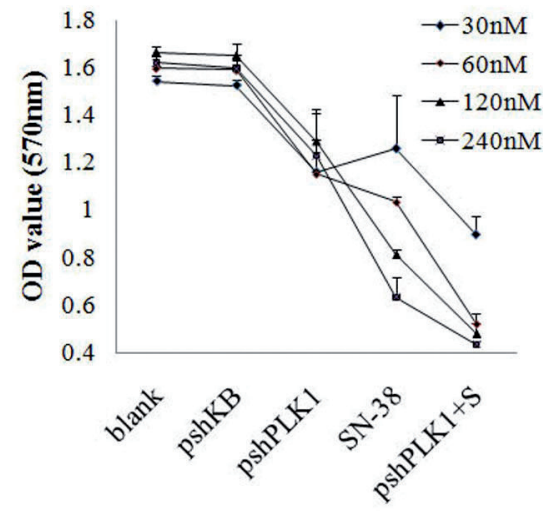

Figure 2. The effect on cell proliferation and apoptosis in vitro

(A) Clone formation assay. Cells were stained with crystal violet after treated for 72 hours. Combination group resulted in fewest clone numbers compared with pshPLK1 or SN-38 monotherapy. (B) Dates were expressed as means \pm SD (for each group, n=3). (C) MTT assay. SW620 cells were transfected with pshPLK1 for $24 \mathrm{~h}$ before $\mathrm{SN}-38$ was added with different concentration $(30,60,120,240 \mathrm{nM})$. After 72 hours, we examined the absorbance at 570 nm. The pshPLK1 combined with SN-38 $(60 \mathrm{nM})$ is more significant $(\mathrm{p}<0.01)$ compared with monotherapy. Cells were analyzed for each sample in triplicate.

(D) Flow cytometry. The combination treatment revealed that pshPLK1 combined with SN-38 increased the number of apoptosis compared with pshPLK1 alone or SN-38 alone treatment. Dates were expressed as means \pm SD (for each group, $n=3$ ).

in nude mice. Our findings showed that the combination group suppressed tumor volume $(\mathrm{p}<0.01)$ compared with control group. As shown in Fig.3A, either pshPLK1alone or CPT-11 alone also resulted in tumor growth inhibition, both $\mathrm{p}<0.01$. Moreover, the tumor weight was weighed at the termination of animal experiment. Mean tumor weight in each group was as follows: $1.365 \pm 0.21 \mathrm{~g}$ (5\%GS group), $1.298 \pm 0.20 \mathrm{~g}$ (pshKB group), $0.8125 \pm 0.13 \mathrm{~g}$ (pshPLK1 group), $0.691 \pm 0.07 \mathrm{~g}$ (CPT-11 group) and $0.3955 \pm 0.03 \mathrm{~g}$ (pshPLK1+CPT-11 group) (Fig.3B). Comparing with control group, combination treatment reduced the tumor weight $(\mathrm{p}<0.01)$.

To confirm that therapeutic effects were attributed to specifically down-regulate PLK1 expression rather than nonspecific reaction. Western blot and Immunohistochemistry were used to examine the expression of PLK1 in the tumor tissues. As shown in Fig.3C, the reduction of PLK1 protein expression was detected in pshPLK1 group and combination group. We also observed general decrease of PLK1 positive cells in treated with pshPLK1 groups; The tumors administrated with $\mathrm{pshKB}$ exhibited more PLK1 positive staining (Fig.3D). These results showed there was no off-target effect in process of therapy.

The effect on cell proliferation and apoptosis in vivo. The PCNA staining was used to evaluate tumor cellular proliferation. As shown in Fig. 4A, the PCNA-positive staining cells reduced in tumors of the mice treated with pshPLK1 alone or CPT-11 alone compared with control group. The obviously reduction of PCNA-positive cells was observed in combination group $(p<0.001)$ and there was no significant difference between 5\% GS and pshKB groups. We used Caspase 3 staining to measure the effect on apoptosis. As shown in Fig.4B, 5\%GS and pshKB groups yielded almost no apoptosis responses in tumors. Treatment with pshPLK1 alone or with CPT-11 alone 
A

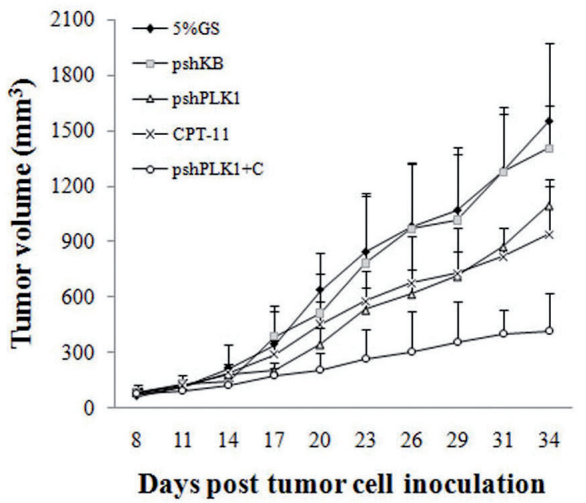

B

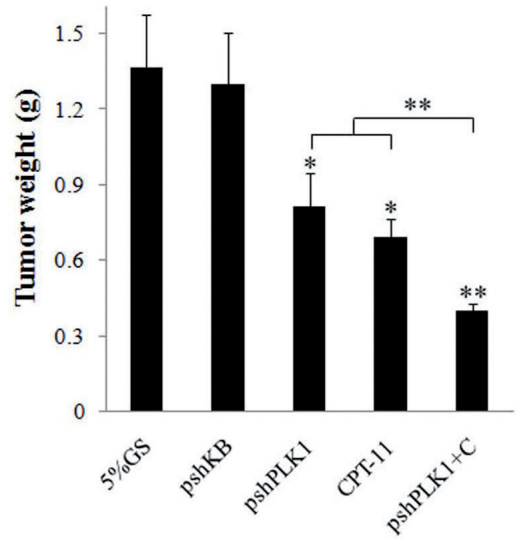

$\mathrm{C}$

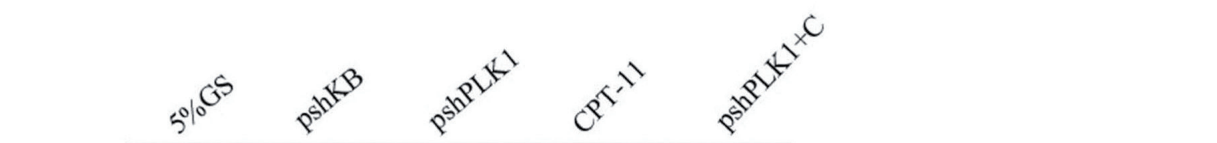

PLK1

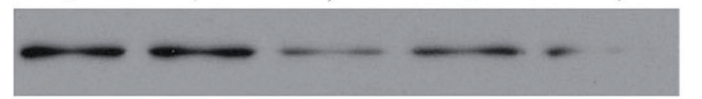

GAPDH

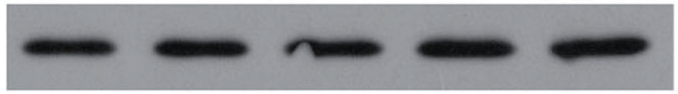

$\mathrm{D}$

$5 \% \mathrm{GS}$

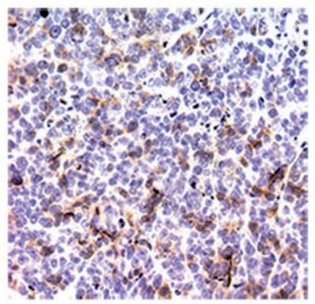

CPT-11

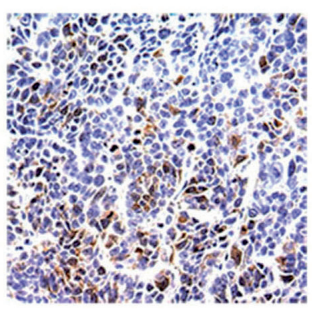

pshKB

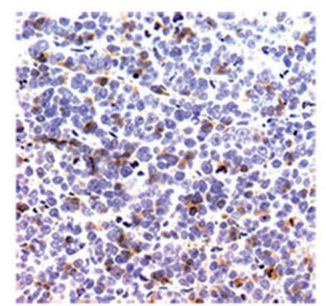

pshPLK1+C

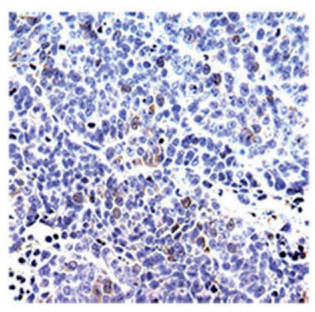

pshPLK1

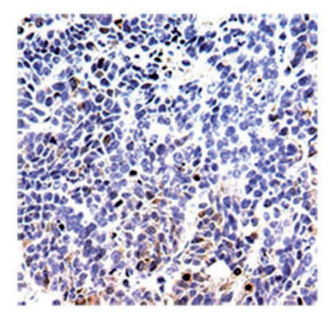

Figure 3. Tumor growth suppression and knockdown of PLK1 expression in vivo

Tumor-bearing mice (4 mice per group) were treated as described in Materials and Methods. (A) Suppression of s.c. tumor growth in mice. Combination treatment led to tumor growth inhibition versus $5 \%$ GS controls $(\mathrm{p}<0.01)$. (B) Mice were sacrificed after treated for 4 weeks and peeled out tumors to weight. ( for each group, $n=4)$. (C) Knockdown of PLK1 expression in mice. Western bolt was employed to detect PLK1 protein expression. The results showed PLK1 was down-regulated in groups treated with pshPLK1 and GAPDH as a control. (D) Tumor tissues from tumor-bearing mice were immunostained with PLK1, to evaluate the expression level of PLK1. Original magnification $\times 400$.

gave a general increase. Combination group led to tumors with high level of apoptosis $(\mathrm{p}<0.001)$. Also, we measured apoptosis by in situ TUNEL staining and similar results were given $(\mathrm{p}<0.001)$ (Fig.4C). In conclusion, combination treatment is efficacy on anti-proliferation and on inducing apoptosis in SW620 tumor xenograft model.
To further evaluate the molecular mechanism of knockdown of PLK1 combined with SN-38 on cell proliferation and apoptosis, we finally examined the expression level of PCNA and cleaved PARP. After combination treatment, PCNA level was decreased more than these treated alone. Cleaved PARP was also sequentially increased (Fig.5). 



Figure 4. Analysis of cell proliferation and apoptosis in vivo

(A) Percentages of PCNA positive cell nuclei were decreased in combination group compared with other groups. Original magnification $\times 400$. (B) In combination group, caspase 3 positive cells were increased. Original magnification $\times 400$. (C) TUNEL assay showed the combination group elevated apoptosis in tumors compared with pshPLK1 alone or CPT-11 alone treatment. Original magnification $\times 200$.

\section{Discussion}

CPT-11 is widely employed to treat variety of human tumors in clinical treatment which is converted into the active metabolite SN-38 that possesses a much higher cytotoxicity against tumor cells in vitro $[27,28]$. Its novel and unique mechanism of action involves inhibition of type I DNA topoisomerase (topoisomerase I) through the formation of stable topoisomerase I-DNA cleavable complexes [29, 30]. Although it is powerful to treat cancers, deficiencies often follow, such as resistance, delayed diarrhoea and so on. So, improving the sensibility of the drugs or to look for new targets is necessary in cancer care.

Previous studies demonstrate that PLK1 is over-expressed in some tumor types, which can be a potential target for cancer therapy. Several RNA interference approaches targeting PLK1 have been investigated and gained certain success in kinds of tumor types. Numerous evidences indicated PLK1 


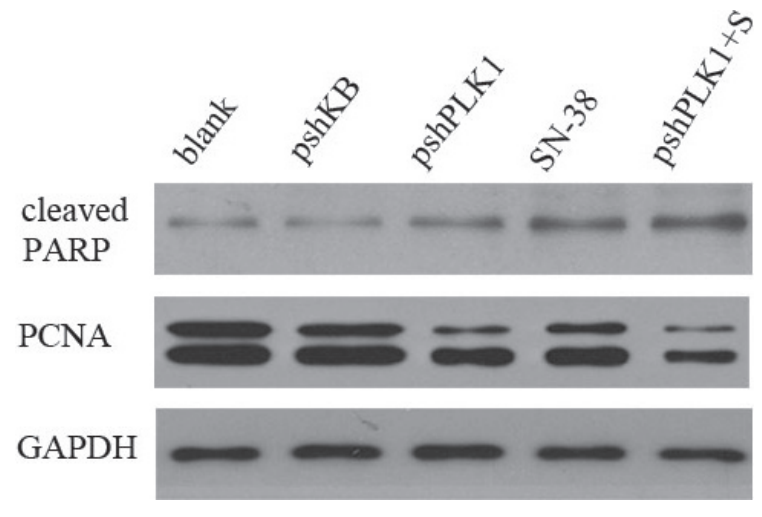

Fig. 5 The effect on expression of PCNA and cleaved PARP Proteins were extracted from untreated SW620 cells and cells treated with pshKB, pshPLK1, SN-38, pshPLK1+SN-38. Western blot was conducted with the indicated protein in SW620 cells. Equal proteins were loaded each gel lane.

expression level was down-regulated in many tumor types by RNA interference, for instance, breast cancer, stomach cancer, head and neck squamous cell carcinomas, colorectal cancer and a panel of other human cancers [31]. Series of previous studies also suggested knockdown of PLK1 by synthetic siRNA could inhibit cell proliferation, and promote the sensibility of breast cancer cells [15]. RNA interference can be achieved through exogenous application of synthetic siRNA or endogenous expression using plasmid or virus vector. However, the safety of recombinant virus vectors must be considered. Meanwhile, chemically synthesized siRNA has been shown to have a short half-life. Previous evidences demonstrated that shRNA offers several important advantages over siRNA including high stability and lower immunity in vivo [32]. To increase intravenous DNA delivery, we also used DOTAP:Chol liposomes to form complexes with DNA, which resulted in enhanced expression of targeted genes in most tissues examined [33]. In our study, we employed PLK1-targeted shRNA to treat SW620 xenograft model for a week, later combined low-dose CPT-11. This combination strategy reduced the dosage of CPT-11, induced apoptosis, inhibited cellular proliferation and slows down the growth of tumors significantly.

Further we investigated the molecular mechanisms of down-regulation of PLK1 increasing the sensibility of cells toward SN-38. We suppose down-regulation of PLK1 may impact several other proteins and factors which interfere the stablity of tumor cells to make external pressure, such as $\mathrm{SN}-38$, penetrate and lead to tumor cells death or downregulation of PLK1 increases expression of some proteins which just on the pathway SN-38 works. Since PLK1 regulates to assemble mitotic spindles, so silencing PLK1 may contribute to disturb the integrity of the mitotic apparatus and further lead to mitotic arrest[34]. This condition may facilitates SN-38 to exert cytotoxicity to kill tumor cells. Fur- thermore, apoptosis signaling pathways are refered. These pathways can be divided into two components involving the mitochondria pathway and FAS pathway [35]. The former involves the release of cytochrome $c$ from the intermembrane space. The latter is mediated by death receptors. Both important protein families, BCL2 and IAP, are involved in apoptosis signal pathways. BCL2 family members (BAX, $\mathrm{BAK}, \mathrm{BAD}$ and BID) promote the release of cytochrome $c$ to make programmed cell death. Death receptors of the TNF family represents promising targets. Activated caspase8, downstream of TRAIL, amplifies the death signal by activating the mitochondria pathway through the $\mathrm{BCL}_{2}$ family. This results in activating caspase9. Both caspase 8 and caspase 9 further activate downstream caspase3. Silencing PLK1 increases the activity of caspase 3 and caspase 7 and CPT- 11 elevates the expression of caspase 3 were reported [36]. So caspase 3 is a joint which both PLK1 and CPT-11 function in SW620 tumor cells. Based-schedule in our experiments shows the expression of caspase 3 is up-regulated in combination treatment group from immunohistochemistry. Cleaved PARP, a product cleaved by caspase3, was also increased in western bolt. So, our experiments indicated the inferences above, other mechanisms yet to be quested. Meanwhile, we investigated the enhanced apoptosis through flow cytometric analysis. Similarity was observed between the results of flow cytometric analysis and the activity of the cleaved PARP. In vivo, PCNA was analyzed by immunohistochemistry and apoptosis was analyzed by TUNEL assay, these expression levels are coincident with the results in vitro. All the results both of anti-proliferation and inducing apoptosis satisfied inhibition of tumor growth. We found the efficacy of combination treatment is more significant than treatment alone. The schedule not only decreases toxicity from CPT-11, but also achieves the efficacy comparing with other strategies

The advantages in our strategy are making SW620 cells sensitive to CPT-11, reducing the dosage of CPT-11 and overcoming resistance. Adverse toxicity was not observed during the treatment because the dose about CPT-11 was screened prior to administration since the diarrhea and hematological effects often appeared with usage of CPT-11 at a high dose. In summary, knockdown of PLK1 by RNA interference combined with CPT-11 to treat colorectal carcinoma is a feasible choice, since it is safe and efficient.

In conclusion, we demonstrated that knockdown of PLK1 by shRNA combination with low-dose CPT-11 increased apoptosis and inhibited proliferation during the treatment of SW620 tumor xenograft model. It is hoped that down-regulating PLK1 by shRNA for targeting therapy could combine other agents to treat more cancer types.

Acknowledgements: This work was supported by Major Special Projects of National Drug Discovery (2012ZX09103301-019) and the National Key Basic Research Program (973 Program) of China (2010CB529900). 


\section{References}

[1] WINKLES JA, ALBERTS GF. Differential regulation of polo-like kinase 1, 2, 3, and 4 gene expression in mammalian cells and tissues. Oncogene 2005; 24: 260-266. http://dx.doi. org/10.1038/sj.onc.1208219

[2] HOLTRICH U, WOLF G, BRAUNINGER A, KARN T, BOHME B et al. Induction and down-regulation of PLK, a human serine/threonine kinase expressed in proliferating cells and tumors. Proceedings of the National Academy of Sciences 1994; 91: 1736. http://dx.doi.org/10.1073/pnas.91.5.1736

[3] TAKAI N, HAMANAKA R, YOSHIMATSU J AND MIYAKAWA I. Polo-like kinases (Plks) and cancer. Oncogene 2005; 24: 287-291. http://dx.doi.org/10.1038/si.onc.1208272

[4] SMITH MR, WILSON ML, HAMANAKA R, CHASE D, KUNG H et al. Malignant transformation of mammalian cells initiated by constitutive expression of the polo-like kinase. Biochemical and biophysical research communications 1997; 234: 397. http://dx.doi.org/10.1006/bbrc.1997.6633

[5] SPANKUCH B, KURUNCI-CSACSKO E, KAUFMANN M and STREBHARDT K. Rational combinations of siRNAs targeting Plk1 with breast cancer drugs. Oncogene 2007; 26:. 5793-5807. http://dx.doi.org/10.1038/sj.onc.1210355

[6] OLMOS D, SWANTON C AND DE BONO J. Targeting pololike kinase: learning too little too late? Journal of Clinical Oncology 2008; 26: 5497-5499. http://dx.doi.org/10.1200/ JCO.2008.18.6585

[7] SCHWARTZ GK, SHAH MA. Targeting the cell cycle: a new approach to cancer therapy. Journal of Clinical Oncology 2005; 23: 9408. http://dx.doi.org/10.1200/JCO.2005.01.5594

[8] SPANKUCH B, MATTHESS Y, KNECHT R, ZIMMER $B$, KAUFMANN $M$ et al. Cancer inhibition in nude mice after systemic application of U6 promoter-driven short hairpin RNAs against PLK1. Journal of the National Cancer Institute2004; 96: 862-872. http://dx.doi.org/10.1093/jnci/ djh146

[9] LIU X, ERIKSON RL. Polo-like kinase (Plk) 1 depletion induces apoptosis in cancer cells. Proceedings of the National Academy of Sciences 2003; 100: 5789. http://dx.doi. org/10.1073/pnas.1031523100

[10] KOIDA N, OZAKI T, YAMAMOTO H, ONO S, KODA T et al. Inhibitory role of Plk1 in the regulation of p73-dependent apoptosis through physical interaction and phosphorylation. Journal of Biological Chemistry 2008; 283: 8555-8563. http:// dx.doi.org/10.1074/jbc.M710608200

[11] SPANKUCH-SCHMITTB, BEREITER-HAHNJ,KAUFMANN M, STREBHARDT K. Effect of RNA silencing of polo-like kinase-1 (PLK1) on apoptosis and spindle formation in human cancer cells. Journal of the National Cancer Institute 2002; 94 : 1863-1877. http://dx.doi.org/10.1093/jnci/94.24.1863

[12] REAGAN-SHAW S, AHMAD N. Silencing of polo-like kinase (Plk) 1 via siRNA causes induction of apoptosis and impairment of mitosis machinery in human prostate cancer cells: implications for the treatment of prostate cancer. The FASEB journal 2005; 19: 611-613.

[13] SPANKUCH-SCHMITT B, WOLF G, SOLBACH C, LOIBL S, KNECHT R et al. Downregulation of human polo-like kinase activity by antisense oligonucleotides induces growth inhibition in cancer cells. Oncogene 2002; 21: 3162. http://dx.doi. org/10.1038/sj.onc. 1205412

[14] GUMIREDDY K, REDDY M, COSENZA SC, NATHAN RB, BAKER SJ et al. ON01910, a non-ATP-competitive small molecule inhibitor of Plk1, is a potent anticancer agent. Cancer Cell 2005; 7: 275-286. http://dx.doi.org/10.1016/ j.ccr.2005.02.009

[15] SPANKUCH B, HEIM S, KURUNCI-CSACSKO E, LINDENAU C, YUAN J et al. Down-regulation of Polo-like kinase 1 elevates drug sensitivity of breast cancer cells in vitro and in vivo. Cancer research 2006; 66: 5836. http://dx.doi. org/10.1158/0008-5472.CAN-06-0343

[16] BOVEN E, MASSARD C, ARMAND J, TILLIER C, HARTOG $\mathrm{V}$ et al. A phase I, dose-finding study of sunitinib in combination with irinotecan in patients with advanced solid tumours. British journal of cancer 2010; 103: 993-1000. http://dx.doi. org/10.1038/sj.bjc.6605852

[17] SCHOEMAKER N, KUPPENS I, MOISEYENKO V, GLIMELIUS B, KJAER $M$ et al. A randomised phase II multicentre trial of irinotecan (CPT-11) using four different schedules in patients with metastatic colorectal cancer. British journal of cancer 2004; 91: 1434-1441.

[18] VAN ARK-OTTE J, KEDDE M, VAN DER VIJGH W, DINGEMANS A, JANSEN W et al. Determinants of CPT11 and SN-38 activities in human lung cancer cells. British journal of cancer 1998; 77: 2171. http://dx.doi.org/10.1038/ bjc. 1998.362

[19] CUNNINGHAMM D, PYRHONEN S, JAMES RD, PUNT CJA, HICKISH TF et al. Randomised trial of irinotecan plus supportive care versus supportive care alone after fluorouracil failure for patients with metastatic colorectal cancer. The Lancet 1998; 352: 1413-1418. http://dx.doi.org/10.1016/ S0140-6736(98)02309-5

[20] ROUGIER P, VAN CUTSEM E, BAJETTA E, NIEDERLE $\mathrm{N}$, POSSINGER $\mathrm{K}$ et al. Randomised trial of irinotecan versus fluorouracil by continuous infusion after fluorouracil failure in patients with metastatic colorectal cancer. The Lancet 1998; 352: 1407-1412. http://dx.doi.org/10.1016/ S0140-6736(98)03085-2

[21] DOUILLARD JY, CUNNINGHAM D, ROTH A, NAVARRO $\mathrm{M}$, JAMES R et al. Irinotecan combined with fluorouracil compared with fluorouracil alone as first-line treatment for metastatic colorectal cancer: a multicentre randomised trial. The Lancet 2000; 355: 1041-1047. http://dx.doi.org/10.1016/ S0140-6736(00)02034-1

[22] SALTZ LB, COX JV, BLANKE C, ROSEN LS, FEHRENBACHER L et al. Irinotecan plus fluorouracil and leucovorin for metastatic colorectal cancer. New England Journal of Medicine 2000; 343: 905-914. http://dx.doi.org/10.1056/ NEJM200009283431302

[23] MROZEK E, KOLESAR J, YOUNG D, ALLEN J, VILLALONA-CALERO $\mathrm{M}$ et al. Phase II study of sequentially administered low-dose mitomycin-C (MMC) and irinotecan (CPT-11) in women with metastatic breast cancer (MBC). Annals of oncology 2008; 19: 1417. http://dx.doi.org/10.1093/ annonc/mdn 154 
[24] FONT A, SALAZAR R, MAUREL J, TARON M, RAMIREZ JL et al. Cisplatin plus weekly CPT-11/docetaxel in advanced esophagogastric cancer: a phase I study with pharmacogenetic assessment of XPD, XRCC3 and UGT1A1 polymorphisms. Cancer chemotherapy and pharmacology 2008; 62: 10751083. http://dx.doi.org/10.1007/s00280-008-0700-3

[25] VASILE E, MASI G, FORNARO L, CUPINI S, LOUPAKIS F et al. A multicenter phase II study of the combination of oxaliplatin, irinotecan and capecitabine in the first-line treatment of metastatic colorectal cancer. British journal of cancer 2009; 100: 1720-1724. http://dx.doi.org/10.1038/sj.bjc.6605075

[26] NEUMANN B, HELD M, LIEBEL U, ERFLE H, ROGERS P et al. High-throughput RNAi screening by time-lapse imaging of live human cells. Nature methods 2006; 3: 385-390. http://dx.doi.org/10.1038/nmeth876

[27] KAWATO Y, AONUMA M, HIROTA Y, KUGA H, SATO K. Intracellular roles of $\mathrm{SN}-38$, a metabolite of the camptothecin derivative CPT-11, in the antitumor effect of CPT-11. Cancer research 1991; 51: 4187.

[28] UENO M, NONAKA S, YAMAZAKI R, DEGUCHI N, MURAI M. SN-38 induces cell cycle arrest and apoptosis in human testicular cancer. European urology 2002; 42:390-397. http://dx.doi.org/10.1016/S0302-2838(02)00321-4

[29] TANIZAWA A, FUJIMORI A, FUJIMORI Y, POMMIER Y. Comparison of topoisomerase I inhibition, DNA damage, and cytotoxicity of camptothecin derivatives presently in clinical trials. Journal of the National Cancer Institute 1994; 86: 836-842. http://dx.doi.org/10.1093/jnci/86.11.836
[30] ARMAND J, DUCREUX M, MAHJOUBI M, ABIGERGES D, BUGAT R et al. CPT-11 (irinotecan) in the treatment of colorectal cancer. European Journal of Cancer 1995; 31: 1283-1287. http://dx.doi.org/10.1016/0959-8049(95)00212-2

[31] DEGENHARDT Y, LAMPKIN T. Targeting Polo-like kinase in cancer therapy. Clinical Cancer Research 2010; 16: 384. http://dx.doi.org/10.1158/1078-0432.CCR-09-1380

[32] PAI SI, LIN YY, MACAES B, MENESHIAN A, HUNG CF et al. Prospects of RNA interference therapy for cancer. Gene Therapy 2006; 13: 464-477. http://dx.doi.org/10.1038/ sj.gt.3302694

[33] CHRISTENSEN CL, GJETTING T, POULSEN TT. Targeted cytosine deaminase-uracil phosphoribosyl transferase suicide gene therapy induces small cell lung cancer-speciic cytotoxicity and tumorgrowth delay. Clinical Cancer Research 2010; 16: 2308-2319. http://dx.doi.org/10.1158/1078-0432.CCR09-3057

[34] FESIK SW. Promoting apoptosis as a strategy for cancer drug discovery. Nature Reviews Cancer 2005; 5: 876-885. http:// dx.doi.org/10.1038/nrc1736

[35] XU WJ, ZHANG S, YANG Y, ZHANG N, WANG W et al. Efficient Inhibition of Human Colorectal Carcinoma Growth by RNA Interference Targeting Polo-Like Kinase 1 In Vitro and In Vivo. Cancer Biotherapy and Radiopharmaceuticals 2011.

[36] DAI W, COGSWELL JP. Polo-like kinases and the microtubule organization center: targets for cancer therapies. Progress in cell cycle research 2003; 5: 327. 